\title{
Article \\ Evaluating the Effect of Visitor Presence on Nile Crocodile (Crocodylus niloticus) Behavior
}

\author{
Alex Riley, Megan Terry, Hani Freeman, Andrew C. Alba (D), Joseph Soltis and Austin Leeds *(D) \\ Animals, Science and Environment, Disney's Animal Kingdom ${ }^{\circledR}$, Lake Buena Vista, FL 32830, USA; \\ alex.x.riley.-nd@disney.com (A.R.); Megan.E.Terry@disney.com (M.T.); hani.d.wild@gmail.com (H.F.); \\ andrew.alba@disney.com (A.C.A.); joseph.soltis@disney.com (J.S.) \\ * Correspondence: austin.leeds@disney.com
}

Citation: Riley, A.; Terry, M.; Freeman, H.; Alba, A.C.; Soltis, J.; Leeds, A. Evaluating the Effect of Visitor Presence on Nile Crocodile (Crocodylus niloticus) Behavior. J. Zool. Bot. Gard. 2021, 2, 115-129. https:// doi.org/10.3390/jzbg2010009

Academic Editor: Katherine A. Cronin

Received: 29 January 2021

Accepted: 9 March 2021

Published: 19 March 2021

Publisher's Note: MDPI stays neutral with regard to jurisdictional claims in published maps and institutional affiliations.

Copyright: (c) 2021 by the authors. Licensee MDPI, Basel, Switzerland. This article is an open access article distributed under the terms and conditions of the Creative Commons Attribution (CC BY) license (https:// creativecommons.org/licenses/by/ $4.0 /)$.

\begin{abstract}
Visitor presence has been shown to affect the behavior of animals in zoos. However, studies to date have not included a wide range of taxonomic groupings, and thus, the effect is poorly understood for many species. Here, we compared the behavior of Nile crocodiles (Crocodylus niloticus) in the presence and absence of visitors for the first time. Data were collected at Disney's Animal Kingdom ${ }^{\circledR}$ over two months during normal operating conditions and during the same two months the following year when the park was closed due to the COVID-19 pandemic, totaling 158 observation hours. Significant differences in crocodile behavior were observed between park operating conditions; however, the direction of change varied by behavior and average differences were generally small. In addition, we found that time of day, temperature and month significantly affected behavior, often with greater magnitude than visitor presence. This highlights the importance of accounting for environmental variables when evaluating and interpreting the behavior, and ultimately welfare, of reptiles in zoos. Collectively, the data suggest the overall effect of visitors on crocodile behavior was small and neutral from a welfare perspective. This study highlights the importance of taxonomic diversity in studying the visitor effect.
\end{abstract}

Keywords: animal behavior; visitor effect; crocodilian; animal welfare; zoo

\section{Introduction}

Among many variables, the presence of other individuals in an animal's environment influences behavior [1], but to what extent is in need of continuing evaluation and research. Animals in zoos can interact with both conspecifics and heterospecifics. The latter can include humans, both familiar individuals such as animal husbandry staff and unfamiliar individuals such as visitors that attend zoos daily. Visitors are a regular part of the lives of animals in zoos and are thus a factor to consider when evaluating animal behavior, generally labeled as the visitor effect [2,3]. Understanding how the behavior of animals in zoos varies in the presence of visitors allows zoo professionals to interpret and provide context for their day-to-day behavior, in addition to evaluating if visitors themselves are influencing animal behavior in ways that may affect animal welfare.

The visitor effect has most often been regarded as a negative influence on animal behavior, having been associated with increased intra-group aggression [4,5], avoidance [6,7], and stereotypic behavior [2,3,5,8,9]. Less commonly, visitor presence is associated with no change in behavior [10-13] or changes that can be categorized as positive such as increased play [14], attention-seeking [15-17], and overall behavioral diversity [18]. It is worth noting that Sherwen and Hemsworth (2019) suggest findings presented in the literature may be biased towards studies identifying potential welfare concerns or to studies capable of producing a significant $P$ value [3]. Thus studies showing no effect may be under reported.

An additional point to consider in the interpretation of results is that findings may not be fully explained by the visitor effect alone. Environmental and social variables are well known to affect animal behavior but are not often fully accounted for and/or 
considered as alternative explanations for behavior variation when studying the visitor effect. Goodenough et al. (2019) recently reported that for ring-tailed lemurs (Lemur catta) in a walk-through exhibit, a situation where a visitor effect may be greater compared to traditional stand-and-view exhibits, time and weather were significant predictors of behavior, and the presence of both reduced the overall statistical effect of visitor presence [19]. Similarly, Collins et al. (2017) found that visitors had limited effects on ring-tailed lemur behavior, while season, weather and time of day had strong effects on behavior [20].

As zoos are dependent on the public to operate [21,22], the majority of studies evaluating the visitor effect have compared varying levels of visitor presence [3] rather than the presence or absence of visitors. Several studies have attempted to experimentally control for visitor presence by moving animals between living spaces visible and not visible to the public [23] or between exhibits exposed to different levels of visitors [24,25]. Experimental evaluations are of significant value to understanding the behavior of animals in zoos, but also create additional confounds, particularly that differences in behavior may not be solely due to variation in visitor presence but also a result of being managed differently and/or in a new environment. Understanding animal behavior in the true absence of visitors within the same environment would provide meaningful insight into understanding the visitor effect. Williams et al. (2021) recently was able to conduct such a study during the recent closures of zoos and aquariums due to the COVID-19 pandemic [26]. They found that during the closure, slender-tailed meerkats (Suricata suricatta) at three institutions engaged in less alert behavior and had increased space use compared to when guests were present and African penguins (Spehniscus demersus) at a single institution had no change in behavior [26].

Sherwen and Hemsworth (2019) reported that 90\% of visitor effect studies focused on mammals, and most commonly species within the primate order (53\%) [3]. Though mammals are popular in zoos, their frequency in the literature is not representative of their frequency in zoo populations [27]. From a perspective of understanding the behavior, and ultimately care and welfare, of animals in zoos, this leaves a large gap in knowledge for non-mammalian taxa, particularly reptiles [28]. In relation to the visitor effect, only one study has been conducted including a reptilian species. Freeland et al. (2020) looked at the behavior of Galapagos tortoise (Chelonoidis nigra) when humans entered their exhibit [29]. The results show that tortoise aggression was greater on days where zoo visitors, accompanied by zoo employees, entered the enclosure and interacted with the tortoises (including physical contact) compared to days with either normal husbandry staff presence or days that included a veterinary staff visit [29]. This singular study, while beneficial as an initial investigation on the potential relationships between visitors and reptilian behavior, illustrates the need for further study to understand how visitor presence affects animal behavior across diverse taxa.

On 16 March 2020, Disney's Animal Kingdom ${ }^{\circledR}$ closed to the public in response to the COVID-19 pandemic, reopening to the public on 7 July 2020. This closure provided a unique opportunity to evaluate animal behavior in the true absence of visitors over an extended period of time. Here we compared the behavior of a large group of male Nile crocodiles (Crocodylus niloticus) living at Disney's Animal Kingdom ${ }^{\circledR}$ during the park closure to that during normal park operations. Since previous research has highlighted that environmental variables may be better predictors of animal behavior than the visitor effect alone $[19,20]$, we also compared crocodile behavior to month, time of day, and temperature.

Social behavior and space use were identified as behavioral measures for this investigation. The Nile crocodiles in this study lived in a relatively large group, thus changes in social dynamics within the group in response to the presence or absence of visitors may affect welfare, as has been reported in visitor effect studies of other species [8,30,31]. For crocodiles, and all reptiles, the ability to thermoregulate is a significant biological function $[32,33]$. Space use is a major behavioral component of thermoregulation for crocodiles and if external stimuli affect a crocodile's ability to properly thermoregulate it may have consequences to individual welfare. To date, crocodiles have received limited study in zoos 
and no studies have focused on the visitor effect. Thus a null hypothesis was developed for this study in relation to the study measures and potential predictor variables.

The Nile crocodile exhibit at Disney's Animal Kingdom ${ }^{\circledR}$ is unique in that visitors are not continually present but rather view the crocodiles in two different experiences: (1) from an open air safari style truck passing in front of the exhibit via an elevated road and (2) specialty small group tours that view the crocodiles from at the rear of the exhibit as well as via rope bridges crossing over the exhibit. The visitor effect is ultimately a behavioral response to the stimuli that visitors create within the zoo environment. Crocodilians are naturally sensitive to and reliant on sound [34-37], vibration [36,38], and visual stimuli [38,39] to navigate their environment. Even though these two viewing experiences are not typical of most zoos, the sensory output of visitor presence, which encompasses both visitors themselves and their transportation, create stimuli that are perceivable by the crocodiles, and thus may have an effect on their behavior. Here it is not possible to separate how stimuli from the visitors or trucks may differentially affect the crocodiles' behavior, thus we are considering them both to be part of the collective visitor presence experience reported in this study.

\section{Materials and Methods}

Twenty-two adult male Nile crocodiles living as a bachelor group at Disney's Animal Kingdom ${ }^{\circledR}$ Theme Park in Lake Buena Vista, Florida, were observed for this study. Individual ages ranged from 31 to 37 years, and all were born in human care. The crocodiles had lived together as a group at Disney's Animal Kingdom ${ }^{\circledR}$ since 1997. The crocodiles lived in an outdoor exhibit consisting of open water, beaches and islands. Visitors primarily viewed the crocodiles from a truck, as part of the Kilimanjaro Safari Ride experience, passing by the exhibit via an elevated road/bridge overlooking the exhibit. Secondarily, the Wild Africa Trek experience was also available as part of an additional paid experience where visitors walked a rope bridge suspended above the exhibit and then viewed the crocodiles from a secured ledge overlooking the back of the exhibit (see Figure 1).

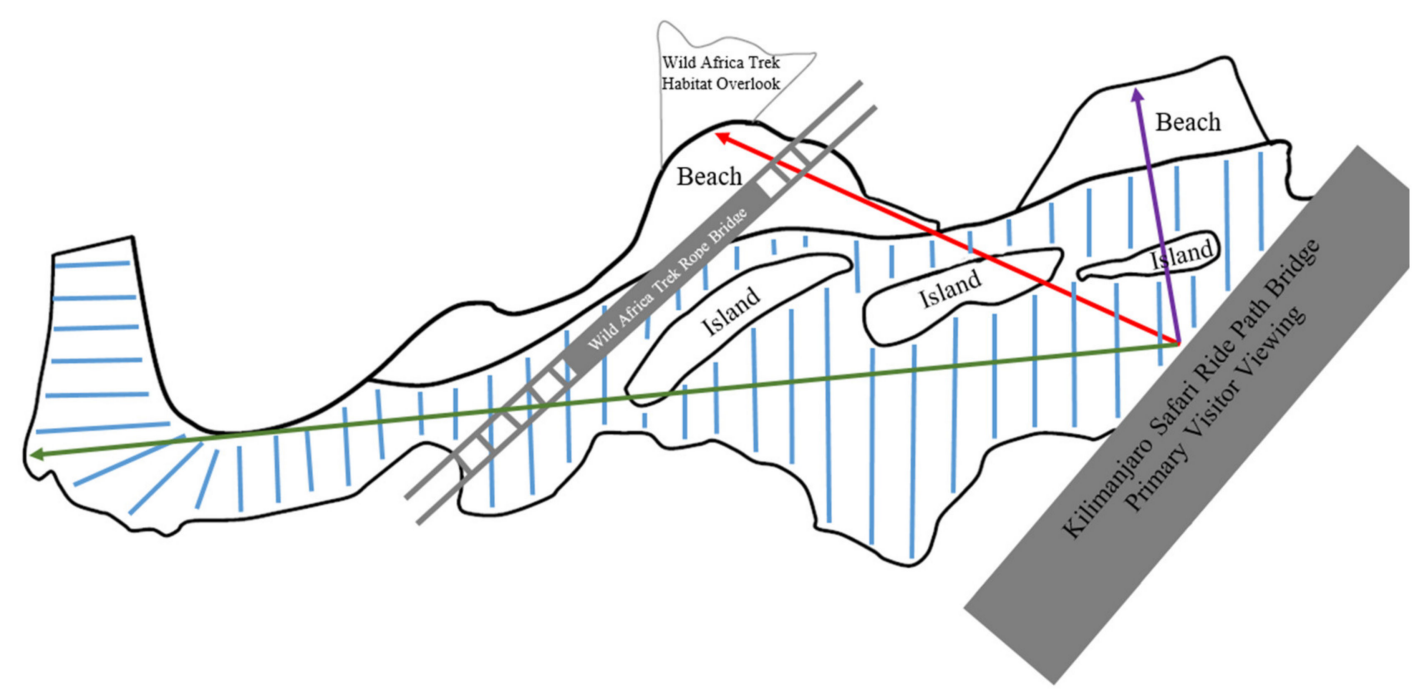

Figure 1. Schematic (not drawn to scale) of Nile crocodile exhibit, approximately $7380 \mathrm{ft}^{2}$ in size. Outer black line denotes habitat containment walls, land areas are labeled as Beach/Island, water area is labeled by blue lines. The Kilimanjaro Safari Ride (KSR) bridge is labeled by grey rectangle. Additional visitor viewing is possible from the Wild Africa Trek (WAT) rope bridge suspended above the habitat and the WAT habitat overlook above the back habitat containment wall. To demonstrate maximum spacing of crocodiles and visitors on KSR, linear distances from center of bridge to habitat edges are labeled by a green, red and purple lines that span approximately 145, 85, and 40 linear feet, respectively.

Crocodile social behavior, social proximity, and space use were recorded. Social behavior was recorded in three categories; agonistic, sociosexual, and conspecific bunting 
behavior (See Table 1). Each of these three social behavior groups were counted at the bout level, where a bout began with the initiation of the behavior and ended after a period of five seconds where no additional behaviors occurred.

Table 1. Ethogram of Nile crocodile behavior.

\begin{tabular}{ccc}
\hline Behavior & Definition & Collection Method \\
\hline Agonistic Behavior & $\begin{array}{c}\text { Aggressive or intolerant behaviors directed from one } \\
\text { crocodile towards a conspecific resulting in physical } \\
\text { contact [40] including bite and jaw clash. A bite was } \\
\text { defined as one crocodile closing one's jaws around a } \\
\text { conspecific, possibly including a roll or shake. Jaw clash } \\
\text { was defined as two crocodiles striking heads together } \\
\text { with their mouths open. }\end{array}$ & All-occurrence sampling \\
Sociosexual Behavior & $\begin{array}{c}\text { The occurrence of mounting, defined as one crocodile } \\
\text { attempting to or successfully climbing onto a conspecific } \\
\text { dorsal-ventrally. Mounting may include the initiator } \\
\text { curling their tail underneath the receiver and grasping } \\
\text { the receiver's body with their feet. }\end{array}$ & All-occurrence sampling \\
\hline Conspecific Bunting & $\begin{array}{c}\text { One crocodile rubbing or pushing their head or body } \\
\text { against the head or body of a conspecific for at least } \\
\text { three seconds. }\end{array}$ & All-occurrence sampling \\
\hline In Contact & $\begin{array}{c}\text { The count of crocodiles in physical contact (touching) } \\
\text { with a conspecific. }\end{array}$ & Scan sampling \\
\hline Space Use & $\begin{array}{c}\text { The count of crocodiles in the water of their exhibit. If a } \\
\text { crocodile had part of their body both in water and on } \\
\text { land they were counted as in water if the majority } \\
(>50 \%) \text { of their body was in water. }\end{array}$ & Scan sampling
\end{tabular}

Data were collected in April and May 2019 at a time when the park was open to visitors (Park Open) and in April and May 2020 when the park was closed to visitors (Park Closed). At the beginning of the data collection period in April 2020, the park had been closed to the public for fifteen days. April and May were selected for comparison because they were the only two months where visitors were not present and ride vehicles were not operating during the closure in 2020. Previous study of this group has demonstrated distinct seasonality in the crocodiles' social behavior (Disney's Animal Kingdom ${ }^{\circledR}$, unpublished data). The month by year approach to data collection utilized here served as a match-control methodology to account for seasonality. Between the two study periods, one crocodile passed away resulting in 21 crocodiles in the Park Closed condition.

Crocodiles were observed during one-hour observations between 0700 and 1600 up to twice a day via video recordings. Video was collected via remote cameras set up throughout the exhibit, covering greater than $90 \%$ of the exhibit space. This system provided greater exhibit coverage than if conducting in person observations and removed observer presence as a cofounding variable. A total of $158 \mathrm{~h}$ of observation were collected over the course of the study balanced by time of day, month and year (See Table 2). All-occurrence sampling was used to record bouts of social behavior at the group level. Social proximity and space use were collected utilizing three group scans (0 min, $30 \mathrm{~min}$ and $60 \mathrm{~min}$ ) within each hour of observation. Data were collected by authors AR and AL, as well as four interns of the Science Operations team at Disney's Animal Kingdom ${ }^{\circledR}$. Interobserver reliability was established amongst all data collectors by double coding one hour videos and maintaining at least $80 \%$ agreement.

Outcome variables for all-occurrence and scan sampling data within each observation were collected as counts, thus generalized linear mixed models (GENLINMIXED; SPSS V.24, IBM; Armonk, NY, USA) were used for analysis as this statistical test (1) accounts for the non-normal distribution of count data and (2) allows for inclusion of random 
variables to account for non-independence of clustered data [41]. Models were run with a Poisson distribution and a log link function. All dependent variables were weighted within each model by the number of visible crocodiles as group visibility varied within and between observations $(\mu=14.8, \mathrm{SE}=0.12)$. Observation date was included as a random variable utilizing a variance components covariance structure. Park status (park open vs. closed), time of day (morning, 7AM through 10AM; midday, 11AM through 2PM; late afternoon, 3PM through 5PM), month (April or May), and temperature $\left({ }^{\circ} \mathrm{F}\right.$ at end of observation) were utilized as fixed factors. Degrees of freedom were determined using a Sattherwaite approximation. Collinearity was undetected within models via inspection of variance inflation factors (all values $<2$; [42,43]). Stepwise model fitting was not utilized to minimize the chance of Type I error and concerns associated with "data dredging" [44,45]. Rather full models were compared to a null model including only the random variable using Akaike information criterion to assess model fit. Likelihood ratio tests found full models had significantly better fits for the agonistic behavior $\left(\chi^{2}=71.8, \mathrm{df}=9, p<0.001\right)$, social proximity $\left(\chi^{2}=27.3, \mathrm{df}=9, p<0.001\right)$ and space use models $\left(\chi^{2}=210.3, \mathrm{df}=9\right.$, $p<0.001)$ compared to their respective null model. Neither the sociosexual behavior model $\left(\chi^{2}=12.0, \mathrm{df}=9, p=0.212\right)$ nor the conspecific bunting behavior model $\left(\chi^{2}=3.8, \mathrm{df}=9\right.$, $p=0.925)$ had a significantly stronger fit than their respective null model. Both sociosexual and conspecific bunting behaviors were relatively infrequent which may have impacted model fit. Though these two models do not significantly fit the dataset better than the null model, they are still included in the Results section for general discussion purposes and because these behaviors were identified as of interest at the initiation of this study, though their outcomes are interpreted conservatively.

Table 2. Number of observations, mean temperatures, and standard errors across all variable conditions.

\begin{tabular}{ccc}
\hline Variable & Number of Observations & Mean Temperatures $\left({ }^{\circ} \mathbf{F}\right)$ \\
\hline All Observations & 158 & $80.4(\mathrm{SE}=0.60)$ \\
Park Open & 79 & $80.5(\mathrm{SE}=0.82)$ \\
Park Closed & 79 & $80.3(\mathrm{SE}=0.88)$ \\
April & 82 & $77.7(\mathrm{SE}=0.86)$ \\
May & 76 & $83.3(\mathrm{SE}=0.69)$ \\
April 2019 & 41 & $76.9(\mathrm{SE}=1.22)$ \\
May 2019 & 38 & $83.9(\mathrm{SE}=0.96)$ \\
April 2020 & 41 & $78.4(\mathrm{SE}=1.21)$ \\
May 2020 & 38 & $82.7(\mathrm{SE}=1.02)$ \\
Morning & 58 & $74.7(\mathrm{SE}=0.88)$ \\
Midday & 56 & $83.9(\mathrm{SE}=0.66)$ \\
Afternoon & 44 & $83.4(\mathrm{SE}=1.04)$ \\
\hline
\end{tabular}

\section{Results}

\subsection{Social Behavior}

Park status $\left(\mathrm{F}_{1,152}=6.603, p=0.011\right)$, month $\left(\mathrm{F}_{1,152}=4.063, p=0.046\right)$, and time of day $\left(\mathrm{F}_{2,152}=31.196, p<0.001\right)$ significantly predicted bouts of agonism (Figure 2$)$. Temperature was not significant $\left(\mathrm{F}_{1,152}=0.032, p=0.859\right)$. Agonism was more frequent in the park closed condition $(\mu=0.27,95 \% \mathrm{CI}=0.12-0.55)$ than the park open condition $(\mu=0.07,95 \%$ $\mathrm{CI}=0.03-0.15)$ and more frequent in the month of April $(\mu=0.23,95 \% \mathrm{CI}=0.11-0.47)$ than month of May ( $\mu=0.08,95 \% \mathrm{CI}=0.04-0.17)$. Pairwise comparisons with a least significant difference adjustment found that bouts of agonism were more frequent in the morning $(\mu=0.20,95 \% \mathrm{CI}=0.12-0.35)$ than midday $(\mu=0.10,95 \% \mathrm{CI}=0.06-0.16 ; \mathrm{t}=3.302, \mathrm{df}=152$, $p<0.001)$ and late afternoon $(\mu=0.12,95 \% \mathrm{CI}=0.07-0.21 ; \mathrm{t}=2.911, \mathrm{df}=152, p=0.004)$. Bouts of agonism were also more frequent in the late-afternoon than midday $(t=2.301$, $\mathrm{df}=152, p=0.023)$. 


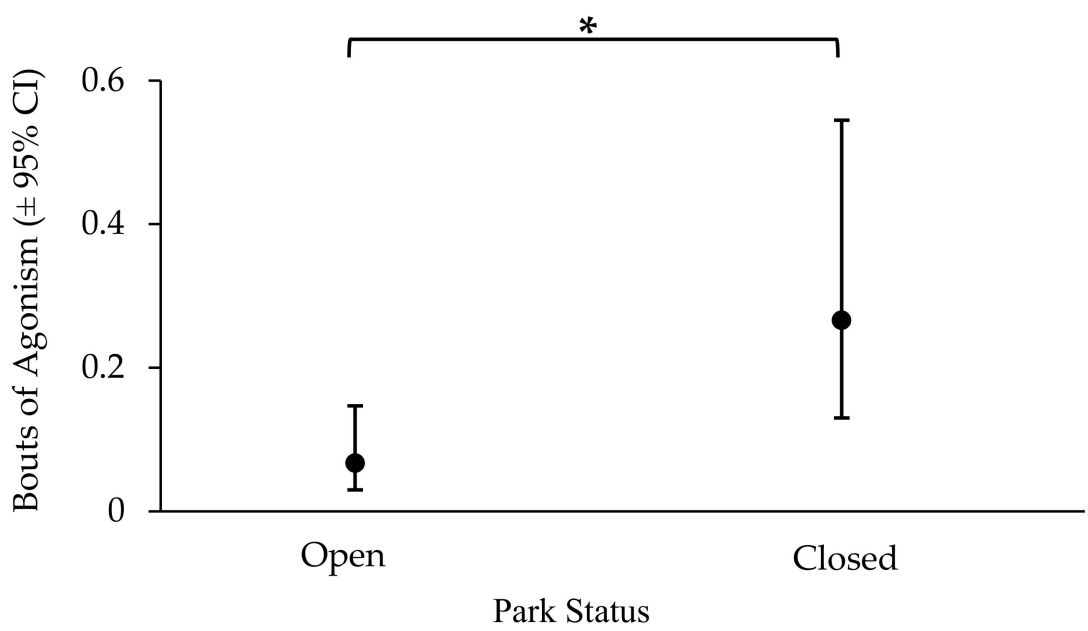

(a)

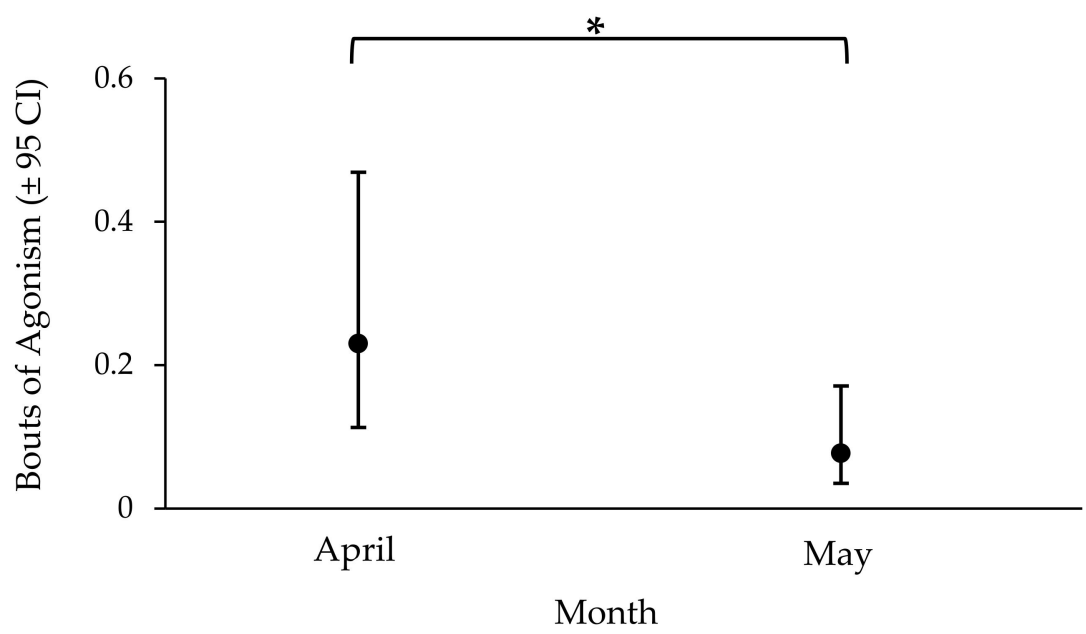

(b)

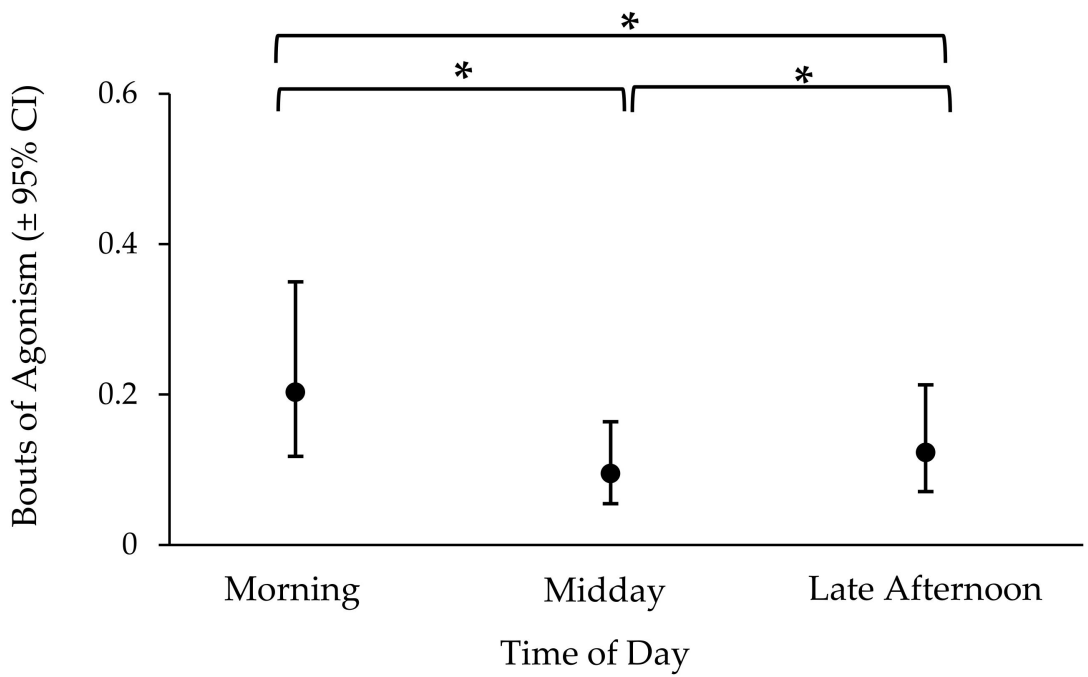

(c)

Figure 2. Estimated marginal mean (EMM) $\pm 95 \%$ confidence interval (CI) for rate of agonistic behavior per observation for (a) park status, (b) month, and (c) time of day. Asterisk $\left({ }^{*}\right)$ denotes statistical significance $(p \leq 0.05)$. 
Month $\left(\mathrm{F}_{1,152}=13.840, p<0.001\right)$ and time of day $\left(\mathrm{F}_{1,152}=51.814, p<0.001\right)$ significantly predicted bouts of sociosexual behavior. Park status $\left(\mathrm{F}_{1,152}=2.432, p=0.121\right)$ and temperature $\left(\mathrm{F}_{1,152}=0.829, p=0.364\right)$ were not significant. Sociosexual behavior was more frequent in April $(\mu=0.05,95 \% \mathrm{CI}=0.02-0.11)$ than May $(\mu=0.002,95 \% \mathrm{CI}=0.001-0.01)$. Pairwise comparisons with a least significant difference adjustment found that sociosexual behavior was more frequent in midday $(\mu=0.03,95 \% \mathrm{CI}=0.01-0.07)$ than morning $(\mu=0.01,95 \% \mathrm{CI}=0.003-0.02 ; \mathrm{t}=2.278, \mathrm{df}=152, p=0.024)$ and late-afternoon $(\mu=0.01$, $95 \% \mathrm{CI}=0.002-0.01 ; \mathrm{t}=2.420, \mathrm{df}=152, p=0.017)$. There was no difference between the morning and late-afternoon frequency $(\mathrm{t}=0.987, \mathrm{df}=152, p=0.325)$.

Park status $\left(\mathrm{F}_{1,152}=6.049, p=0.015\right)$ and time of day $\left(\mathrm{F}_{1,152}=18.050, p<0.001\right)$ significantly predicted conspecific bunting behavior. Month $\left(\mathrm{F}_{1,152}=1.632, p=0.203\right)$ and temperature $\left(\mathrm{F}_{1,152}=0.137, p=0.712\right)$ were not significant. Conspecific bunting behavior was more frequent in the park closed condition $(\mu=0.05,95 \% \mathrm{CI}=0.02-0.10)$ than park open condition ( $\mu=0.01,95 \% \mathrm{CI}=0.004-0.027$ ). Pairwise comparisons with a least significant difference adjustment found that conspecific bunting behavior was more frequent midday $(\mu=0.05,95 \% \mathrm{CI}=0.02-0.09)$ than in late-afternoon $(\mu=0.01,95 \% \mathrm{CI}=0.003-0.02 ; \mathrm{t}=3.001$, $\mathrm{df}=152, p=0.003)$, and more frequent in the morning ( $\mu=0.03,95 \% \mathrm{CI}=0.02-0.07)$ than late-afternoon $(\mathrm{t}=2.586, \mathrm{df}=152, p=0.011)$. There was no difference between the morning and midday rates $(\mathrm{t}=1.290, \mathrm{df}=152, p=0.199)$.

\subsection{Social Proximity}

Park status $\left(\mathrm{F}_{1,467}=4.158, p=0.042\right)$, month $\left(\mathrm{F}_{1,467}=10.043, p=0.002\right)$, time of day $\left(\mathrm{F}_{2,467}=25.407, p<0.001\right)$, and temperature $\left(\mathrm{F}_{1,467}=21.451, p<0.001\right)$ significantly predicted the number of crocodiles in contact with conspecifics (Figure 3). More crocodiles were observed lying in contact with a conspecific when the park was open $(\mu=4.41$, $95 \% \mathrm{CI}=3.51-5.55)$ than closed $(\mu=3.15,95 \% \mathrm{CI}=2.51-3.96)$, and more crocodiles were observed in contact with a conspecific in May $(\mu=4.85,95 \% \mathrm{CI}=3.83-6.13)$ than April $(\mu=2.87,95 \% \mathrm{CI}=2.30-3.59)$. Pairwise comparisons with a least significant difference adjustment found the number of crocodiles in contact with a conspecific was greater in both the morning ( $\mu=4.07,95 \% \mathrm{CI}=3.45-4.79)$ and midday $(\mu=3.79,95 \% \mathrm{CI}=3.22-4.47)$ than late-afternoon $(\mu=3.37,95 \% \mathrm{CI}=2.86-3.97 ; \mathrm{t}=5.798, \mathrm{df}=467, p<0.001 ; \mathrm{t}=5.104$, $\mathrm{df}=467, p<0.001)$, and morning was greater than midday $(\mathrm{t}=2.652, \mathrm{df}=467, p=0.008)$. Temperature was positively associated with proximity with the model estimating a $4.0 \%$ $(95 \% \mathrm{CI}=3.0-6.0 \%)$ increase in the number of crocodiles in proximity for every $5^{\circ} \mathrm{F}$ increase in temperature.

\subsection{Space Use}

Month $\left(\mathrm{F}_{1,467}=4.051, p=0.045\right)$, time of day $\left(\mathrm{F}_{2,467}=121.794, p<0.001\right)$, and temperature $\left(\mathrm{F}_{1,467}=52.861, p<0.001\right)$ were significant predictors of crocodile space use (Figure 4). Park status $\left(\mathrm{F}_{1,467}=0.730, p=0.393\right)$ was not significant. More crocodiles were observed in the water in April $(\mu=8.11,95 \% \mathrm{CI}=7.48-8.80)$ than May $(\mu=7.18,95 \% \mathrm{CI}=6.59-7.83)$. For time of day pairwise comparisons with a least significant difference adjustment found that number of crocodiles in the water significantly decreased from morning $(\mu=8.88,95 \%$ $\mathrm{CI}=8.34-9.46)$ to midday $(\mu=7.84,95 \% \mathrm{CI}=7.38-8.34 ; \mathrm{t}=6.518, \mathrm{df}=467, p<0.001)$ and late-afternoon $(\mu=6.38,95 \% \mathrm{CI}=5.99-6.81 ; \mathrm{t}=13.745, \mathrm{df}=467, p<0.001)$ and from midday to late-afternoon $(\mathrm{t}=11.408, \mathrm{df}=467, p<0.001)$. Temperature was positively associated with space use predicting a $6 \%(95 \% \mathrm{CI}=4.5-7.5 \%)$ increase in crocodiles in water for every $5{ }^{\circ} \mathrm{F}$ increase in temperature. 


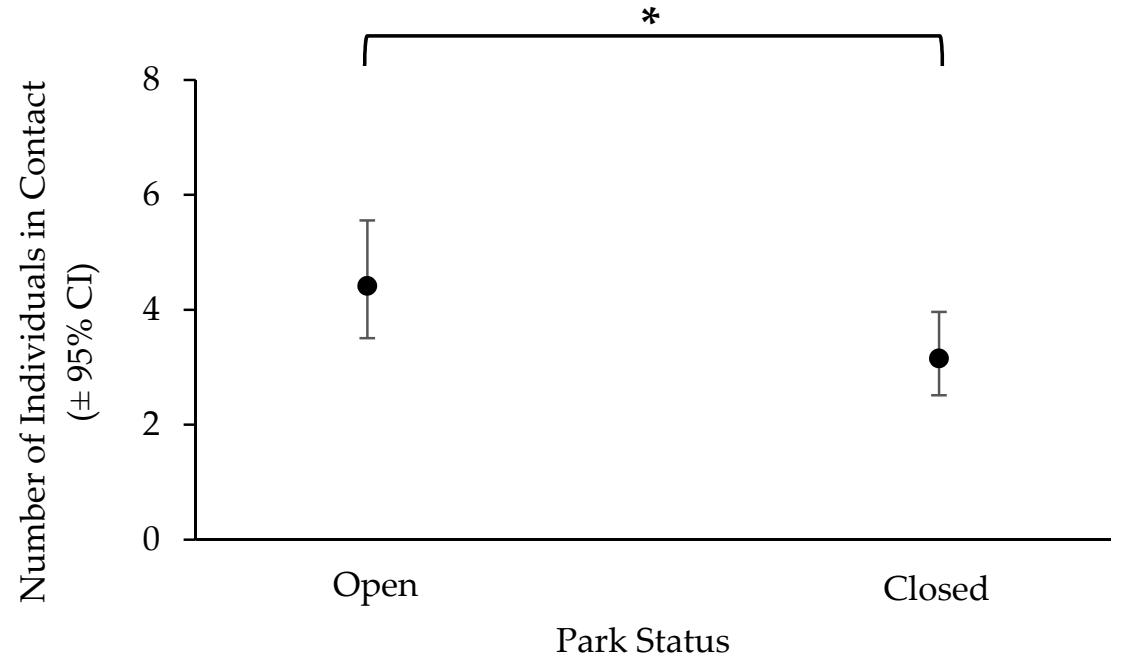

(a)

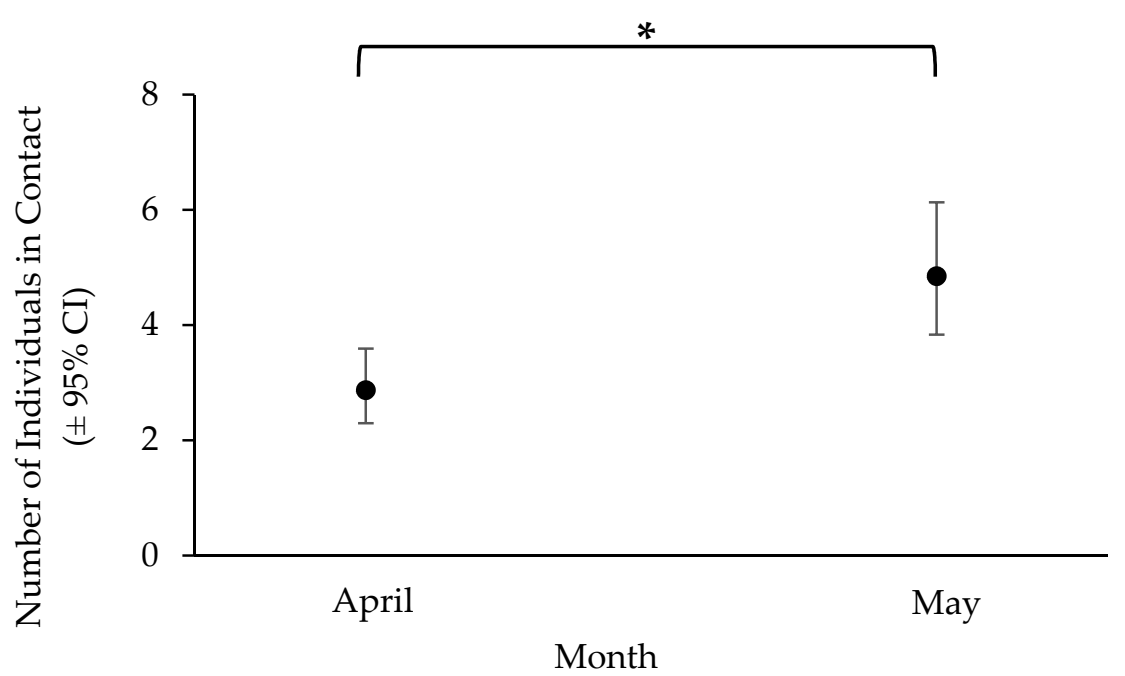

(b)

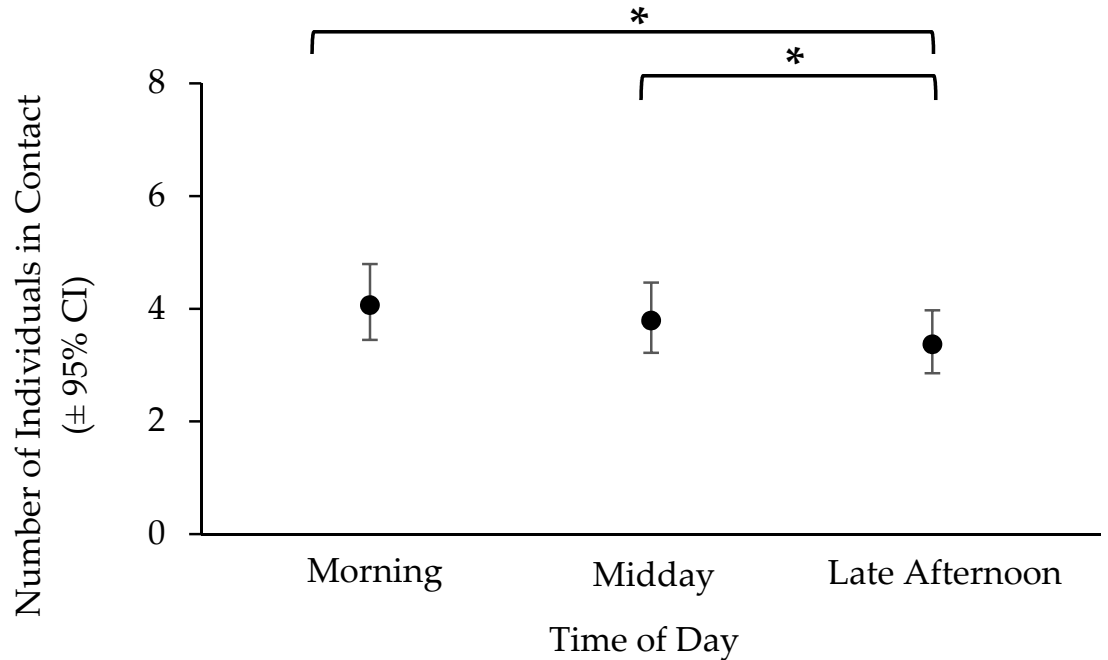

(c)

Figure 3. Estimated marginal mean (EMM) $\pm 95 \%$ confidence interval (CI) for number of individuals in contact per scan for (a) park status, (b) month, and (c) time of day. Asterisk $\left({ }^{*}\right)$ denotes statistical significance $(p \leq 0.05)$. 


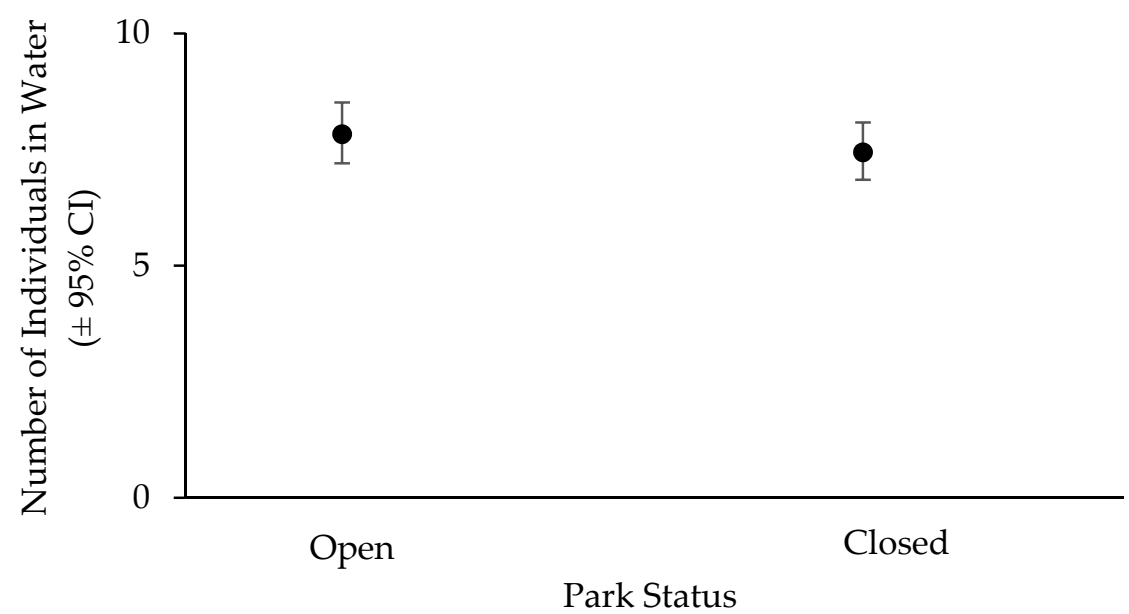

(a)

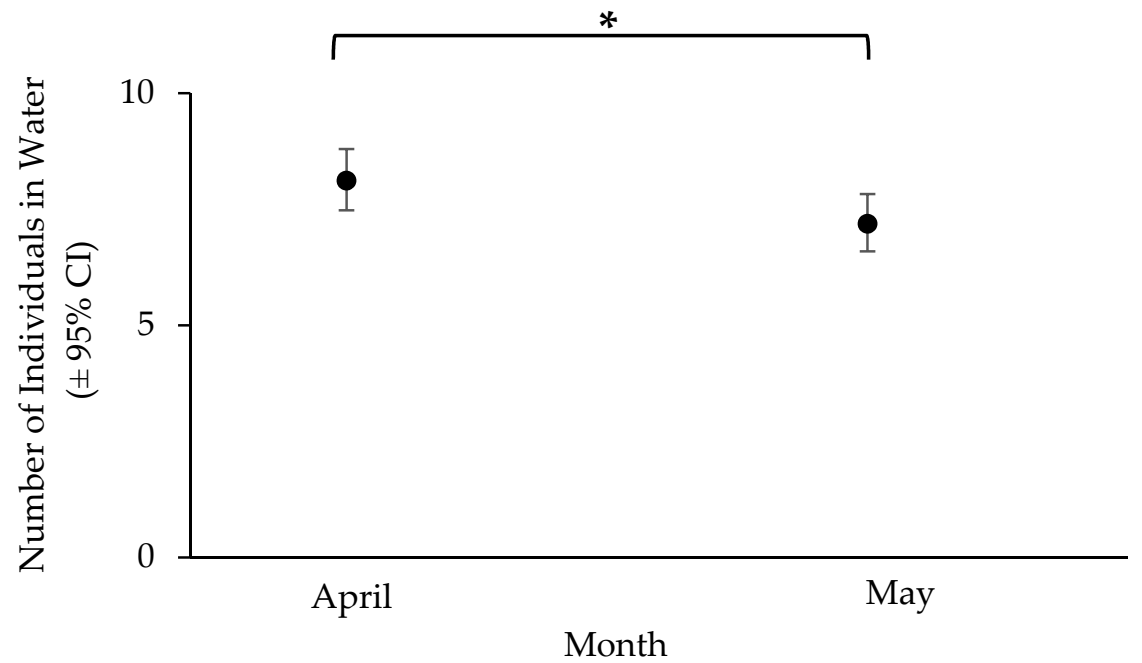

(b)

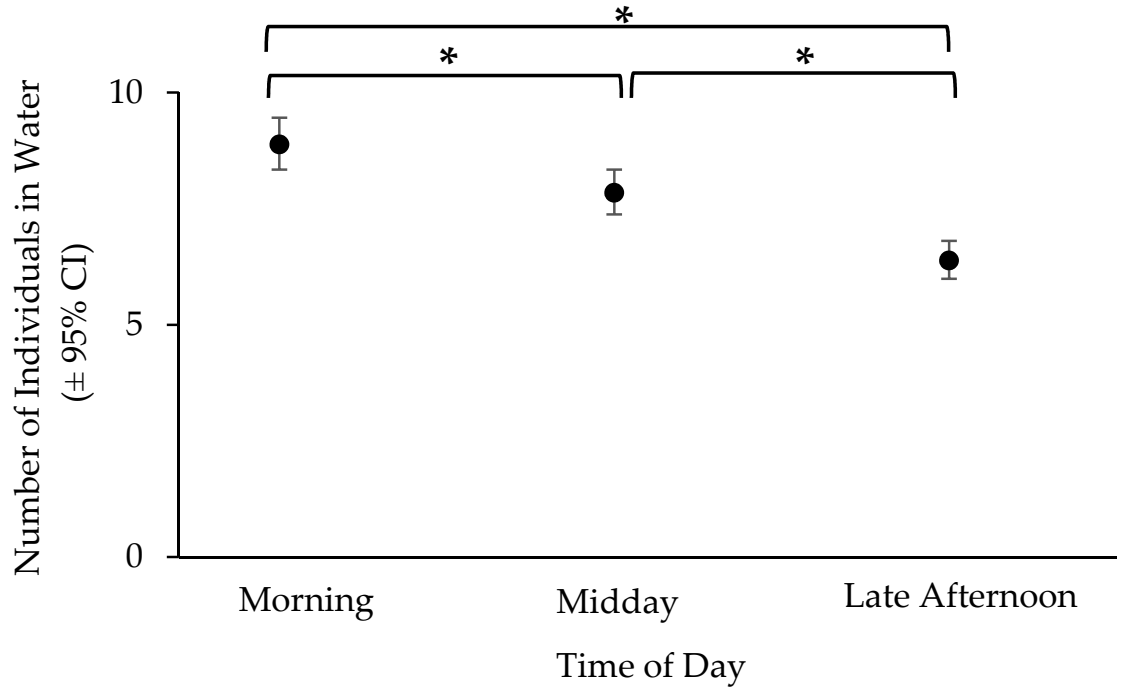

(c)

Figure 4. Estimated marginal mean $(\mathrm{EMM}) \pm 95 \%$ confidence interval $(\mathrm{CI})$ for number of individuals in water per scan for (a) park status, (b) month, and (c) time of day. Asterisk $\left(^{*}\right)$ denotes statistical significance $(p \leq 0.05)$. 


\section{Discussion}

Here we evaluated the presence and absence of visitors on the behavior of a large all-male group of Nile crocodiles. This study represents only the second evaluation of visitor presence on the behavior of a reptilian species and the first to evaluate reptilian behavior in relation to a passive visitor presence. Crocodile behavior did vary between visitor conditions; however, behavior did not follow a consistent pattern, suggesting no obvious positive or negative effect. In addition, the magnitude of difference between conditions was generally low, suggesting any statistical difference may result in limited practical differences in behavior. Environmental variables were also significant predictors of crocodile behavior highlighting the importance of evaluating alternative explanatory variables when investigating the visitor effect on animal behavior, particularly reptiles.

Crocodile behavior significantly differed between visitor presence conditions for three of our five study variables. Of particular note, the direction and magnitude of change varied for each behavior. Agonistic behavior has typically been positively associated with visitor presence $[4,30,31]$; however, here we found that agonistic behavior was greater when visitors were absent. An increase in conspecific bunting behavior when visitors were absent was also observed. Similar behaviors have been described as relating to courtship in crocodilians [38]; however, the functionality of this behavior in this all-male group and this specific species needs further evaluation. An increase in both of these behaviors when visitors were absent could suggest that visitor presence had an overall suppressive effect on crocodile social behavior, though how and why visitor presence would have a suppressive effect is unclear, particularly since multiple studies, albeit in other taxa, have reported meaningful increases in agonism $[4,30,31]$ and decreases in affiliation $[14,30,46]$ with visitor presence. Environmental variables, discussed in more detail later in the discussion, may be a better explanation for behavioral variation in crocodiles, though further detailed study on the social behavior of crocodiles may also provide additional context for understanding the data reported here.

Time in proximity increased when visitors were present. Generally, the tolerance of conspecifics within close proximity can be considered a positive indicator of welfare for group-living species [47,48]; however, increased proximity has also been observed to be associated with the presence of a stressor in some group-living species [49-51]. To better interpret our finding, an increased understanding of crocodile social behavior is needed, though it does appear unlikely that increased social proximity would be a stress coping mechanism given their natural territoriality $[52,53]$. Anecdotally, crocodiles in proximity were often observed on the beach furthest from where the visitors travelled past the exhibit. Thus the increased proximity could also potentially be a function of a desire to be furthest away from visitors, with the increased proximity being an unintentional behavioral outcome. It is worth noting that the mean difference between visitor presence conditions was approximately one more crocodile in proximity to conspecifics when visitors were present. Though statistically significant, this difference may not be biologically significant for a group of 21 individuals. Further evaluations of the individual relationships that crocodiles develop and how those may change in the presence of stressors will be highly informative to better understanding the behavior and welfare of crocodiles in human care. Furthermore, more refined measures of proximity, rather than relying solely in physical contact, may provide additional detail in future evaluations.

Crocodile space use and sociosexual behavior were not affected by visitor presence. Variation in space use has been used to evaluate visitor effect in previous studies $[17,54,55]$. For crocodiles, the ability to regularly spend time on land is important for thermoregulation $[32,56]$. If, in human care, crocodiles are exposed to stressors that inhibit their choices to properly thermoregulate, then their welfare could be compromised. Thus the unobserved difference in space use behavior here suggests any effect(s) visitors may have on crocodiles does not affect their choices in space, which is significant to their proper biological functioning. Similar to the earlier discussed conspecific bunting behavior, the exact function of the sociosexual behavior in this all-male crocodile group is not fully understood, 
but similar behaviors have been associated with dominance $[57,58]$ and stress [59] in other species. Thus it is likely that the lack of effect on sociosexual behavior observed in relation to visitor presence is similarly a positive indicator for the welfare of these individuals.

Overall, visitor presence on crocodile behavior can be summarized as neutral, rather than positive or negative, given individual behaviors were observed to have no consistent pattern of influence. Furthermore, magnitude of differences were generally small and likely better explained by environmental variables. These findings are significant as they suggest, for the first time, that a passive visitor viewing experience does not negatively affect the behavior and welfare of a reptilian species. The Nile crocodiles studied here are an apex predator [60] and thus may be biologically less sensitive to the presence of visitors or other animals within their environment. Future studies that include reptilian species with different natural histories will be informative to better understanding how natural history relates to the visitor effect.

Environmental variables (month, temperature, time of day) were also associated with variation in crocodile behavior. Previous study of this group of crocodiles has found seasonal increases in social behavior (Disney's Animal Kingdom ${ }^{\circledR}$, unpublished data), with the months of March and April demarcating approximately when rates of social behavior begin to decrease. In the wild, Nile crocodiles are observed to exhibit seasonal differences in reproductive behavior and space use $[38,61,62]$. Here we found that rates of agonism and sociosexual behavior and the number of individuals in social proximity were all greater in the month of April than May. These data suggest that seasonality may play a role in the behavior of Nile crocodiles in zoos, though additional study in both nature and zoological settings are needed. A challenge for future studies will be that for many reptilian species, seasonal behavior may also be dependent on other external factors such as exhibit design (e.g., indoor vs. outdoor) or group type (e.g., breeding vs. nonbreeding), further complicating the interpretation of results. Regardless of challenges, seasonality should be considered and accounted for, when applicable, when studying the behavior of reptiles in zoos.

As ectotherms, crocodiles rely on external sources of energy and pay the energetic costs of thermoregulation through behavioral processes [32,33]. Thus it is not surprising that temperature and time of day were significantly associated with behavior in this study, as these factors are key environmental variables associated with thermoregulation in reptiles [56,63]. Of particular note, time of day was the only variable in this study that was a significant predictor of all five behaviors measured. Similar to season, these findings highlight the importance of accounting for environment in the study of reptile behavior. Recently, both Collins et al. (2017) and Goodenough et al. (2019) reported that the behavior of ring tailed lemurs was better predicted by weather and time of day than visitor presence alone $[19,20]$. Furthermore, as many studies of visitor effect are correlational, it is also important to consider that visitor presence itself may be predicted by environmental variables such as temperature and time of day, thus evaluating environmental variables may provide additional context for understanding the nuances associated with visitor presence. In this study, the environmental variables accounted for were relatively simple. As the crocodile exhibit was large and complex, it is likely that microclimates existed within the exhibit, further affecting behavior at an individual level. Future studies may benefit from including more specific environmental measures, such as sampling environmental variables throughout an animal's living space and/or measuring more detailed environmental variables such as sun/light intensity.

Evaluations of reptile behavior and welfare, though increasing [64-66], are still infrequent, occurring at rates well below those of other taxa [28]. With such a strong need to evaluate the welfare of reptiles within zoological parks, one overarching question is where to begin? One approach, and the one we took here, is to identify a research topic that has not emphasized the inclusion of reptilian taxa and develop a comparable methodology with a reptilian species. This approach has similarly been used by other institutions, most recently by Spain et al. (2020) who evaluated the behavior of Madagascar giant hognose 
snakes (Leioheterodon madagascariensis) in relation to exhibit modifications, a topic that has been well evaluated in mammals $[15,64,67,68]$. This suggestion is neither new nor groundbreaking, but one that has not been utilized widely in the field. Such an approach is significant for several reasons. First, the behavior of understudied species are often understudied because it is perceived as difficult to interpret their behavior, particularly in relation to welfare. By evaluating their behavior in contexts that are well studied in other species, an initial comparison point is created to put their behavior, and ultimately welfare, into context. Second, studying their behavior in broader contexts should identify species-specific patterns of behavior that spurs more taxa focused inquires. Finally, this approach strengthens the understanding of these broader topics. Binding et al. (2020) highlighted that $75 \%$ of welfare research published between 2008 and 2017 focused on mammalian species [28]. This translates into poor understanding, broadly speaking, of how topics such as social influences, visitor presence, transportation, and enrichment (to only name a few of the topics summarized in Binding et al. (2020)) relate to the behavior and welfare of non-mammalian animals in zoos [28]. Inclusion of more diverse taxa strengthens the scientific knowledge of the zoo industry. For those looking to evaluate the behavior, and ultimately welfare, of reptiles and other understudied taxa in zoos, a strong recommendation can be made to identify common areas of study and develop studies that can include such taxa.

Understanding if and how visitors affect animal behavior in zoos is significant to interpreting animal behavior and providing optimal care. What makes this topic complex is how diverse the visitor effect can be, not only between zoos but even between individual exhibits within the same institution. Furthermore, the continual evolution of the zoo experience regularly creates novel contexts in which visitors and animals interact. Here we contributed to this area of study by (1) evaluating animal behavior in the true absence of visitors and (2) including a poorly studied species and taxa as the study focus. Collectively, the data reported show inconsistent and minor effects of visitor presence on crocodile behavior, suggesting a generally neutral effect in terms of welfare. Evaluating the behavior of animals in zoos in the absence of visitors is an approach that provides the foundation for ultimately understanding how visitors affect the behavior of animals in human care. With the widespread closures of zoos and aquariums due to COVID-19 in 2020, it is likely that this methodological approach will continue to be explored more in future publications, findings from which should be informative to the field. As this is one of two such studies in reptiles, we hope this study contributes to an increased focus on behavioral research of reptiles in zoos.

Author Contributions: Conceptualization, A.R. and A.L.; methodology, A.R., M.T., H.F., A.C.A., and A.L.; formal analysis, A.L.; data curation, A.R.; writing—original draft preparation, A.R. and A.L.; writing-review and editing, A.R., M.T., H.F., A.C.A., J.S., and A.L. All authors have read and agreed to the published version of the manuscript.

Funding: This research received no external funding.

Institutional Review Board Statement: The methods of this study were approved by the scientific review committee of Disney's Animal Kingdom ${ }^{\circledR}$.

Data Availability Statement: Requests for data should be sent to corresponding author and scientific review committee of Disney's Animal Kingdom ${ }^{\circledR}$ for consideration.

Acknowledgments: We would like to recognize and thank Kristen Wolfe, Scott Krug, Ike Leonard, Andy Daneault and the entire Ituri Forest team at Disney's Animal Kingdom ${ }^{\circledR}$ for their partnership in studying the behavior and welfare of the Nile crocodiles. We would also like to recognize Jenn Andringa for approaching the Science Team to initiate a behavior monitoring project to better understand their behavior and welfare. We could not have completed this study without the assistance of Becca Evey, Cassondra Giarrusso, Kaitlin Grell, and Sarah Boyer with data collection and Eric Renaldo for his technical expertise in supporting our use of the remote camera system.

Conflicts of Interest: The authors declare no conflict of interest. 


\section{References}

1. Bonnie, K.E.; Ang, M.Y.L.; Ross, S.R. Effects of crowd size on exhibit use by and behaviour of chimpanzees (Pan troglodytes) and western lowland gorillas (Gorilla gorilla) at a zoo. Appl. Anim. Behav. Sci. 2016, 178, 102-110. [CrossRef]

2. Hosey, G.R. Zoo animals and their human audiences: What is the visitor effect? Anim. Welf. 2000, 9, 343-357.

3. Sherwen, S.L.; Hemsworth, P.H. The visitor effect on zoo animals: Implications and opportunities for zoo animal welfare. Animals 2019, 9, 366. [CrossRef] [PubMed]

4. Sekar, M.; Rajagopal, T.; Archunan, G. Influence of Zoo Visitor Presence on the Behavior of Captive Indian Gaur (Bos gaurus gaurus) in a Zoological Park. J. Appl. Anim. Welf. Sci. 2008, 11, 352-357. [CrossRef] [PubMed]

5. Wells, D. A note on the influence of visitors on the behavior and welfare of zoo-housed gorillas. App. Anim. Behav. Sci. 2008, 93, 13-17. [CrossRef]

6. Farrand, A.; Hosey, G.; Buchanan-Smith, H.M. The visitor effect in petting zoo-housed animals: Aversive or enriching? Appl. Anim. Behav. Sci. 2014, 151, 117-127. [CrossRef]

7. Chiew, S.J.; Butler, K.L.; Sherwen, S.L.; Coleman, G.J.; Fanson, K.V.; Hemsorth, P.H. Effects of regulating visitor viewing proximity and the intensity of visitor behaviour on the little penguin (Eudyptula minor) behaviour and welfare. Animals 2019, 9, 285. [CrossRef] [PubMed]

8. Bortolini, T.S.; Bicca-Marques, J.C. The effect of environmental enrichment and visitors on the behaviour and welfare of two captive hamadryas baboons (Papio hamadryas). Anim. Welf. 2011, 20, 573.

9. Sellinger, R.L.; Ha, J.C. The effects of visitor density and intensity on the behaviour of two captive jaguars (Panthera onca). J. Appl. Anim. Welf. Sci. 2005, 8, 233-244. [CrossRef] [PubMed]

10. Sherwen, S.L.; Magrath, M.J.; Butler, K.L.; Phillips, C.J.; Hemsworth, P.H. A multi-enclosure study investigating the behavioural response of meerkats to zoo visitors. Appl. Anim. Behav. Sci. 2014, 156, 70-77. [CrossRef]

11. O'Donovan, D.E.; Hindle, J.E.; McKeown, S.; O'Donovan, S. Effect of visitors on the behaviour of female cheetahs, Acinonyx jubatus and cubs. Int. Zoo Yearb. 1993, 32, 238-244. [CrossRef]

12. Margulis, S.W.; Hoyos, C.; Anderson, M. Effect of felid activity on zoo visitor interest. Zoo Biol. 2003, 22, 587-599. [CrossRef]

13. Normando, S.; Pollastri, I.; Florio, D.; Ferrante, L.; Macchi, E.; Isaja, V.; de Mori, B. Assessing Animal Welfare in Animal-Visitor Interactions in Zoos and Other Facilities. A Pilot Study Involving Giraffes. Animals 2018, 8, 153. [CrossRef] [PubMed]

14. Todd, P.A.; Macdonald, C.; Coleman, D. Visitor-associated variation in captive Diana monkey (Cercopithecus diana diana) behaviour. Appl. Anim. Behav. Sci. 2007, 107, 162-165. [CrossRef]

15. Bloomfield, R.C.; Gillespie, G.R.; Kerswell, K.J.; Butler, K.L.; Hemsworth, P.H. Effect of partial covering of the visitor viewing area window on positioning and orientation of zoo orangutans: A preference test. Zoo Biol. 2015, 34, 223-229. [CrossRef] [PubMed]

16. Nimon, A.; Dalziel, F. Cross-species interaction and communication: A study method applied to captive siamang (Hylobates syndactylus) and long-billed corella (Cacatua tenuirostris) contacts with humans. Appl. Anim. Behav. Sci. 1992, 33, $261-272$. [CrossRef]

17. Eltorai, A.E.; Sussman, R.W. The "Visitor Effect" and captive black-tailed prairie dog behavior. Der Zoologische Garten 2010, 79, 109-120. [CrossRef]

18. Collins, C.K.; Quirke, T.; Overy, L.; Flannery, K.; O'Riordan, R. The effect of the zoo setting on the behavioural diversity of captive gentoo penguins and the implications for their educational potential. J. Zoo Aquar. Res. 2016, 4, 85-90.

19. Goodenough, A.E. Are "visitor effects" overestimated? Behaviour in captive lemurs is mainly driven by co-variation with time and weather. J. Zoo Aquar. Res. 2019, 7, 59-66.

20. Collins, C.; Corkery, I.; Haigh, A.; McKeown, S.; Quirke, T.; O’Riordan, R. The effects of environmental and visitor variables on the behavior of free-ranging ring-tailed lemurs (Lemur catta) in captivity. Zoo Biol. 2017, 36, 250-260. [CrossRef]

21. Ballantyne, R.; Packer, J.; Hughes, K.; Dierking, L. Conservation learning in wildlife tourism settings: Lessons from research in zoos and aquariums. Envir. Edu. Res. 2007, 13, 367-383. [CrossRef]

22. Mason, P. Zoo tourism: The need for more research. J. Sust. Tourism. 2000, 8, 333-339. [CrossRef]

23. Glatston, A.R.; van Hoo, J.A.R.A.M.; Geilvoet-Soeteman, E.; Hora-Pecek, E.; Geilvoet-Soeteman, E.; Hora-Pecek, E. The influence of the zoo environment on social behavior of groups of cotton-topped tamarins, Saguinus oedipus oedipus. Zoo Biol. 1984, 3, $241-253$. [CrossRef]

24. Mitchell, G.; Herring, F.; Obradovich, S.; Tromborg, C.; Dowd, B.; Neville, L.E.; Field, L. Effects of visitors and cage changes on the behaviors of mangabeys. Zoo Biol. 1991, 10, 417-423. [CrossRef]

25. Mitchell, G.; Tromborg, C.T.; Kaufman, J.; Bargabus, S.; Simoni, R.; Geissler, V. More on the influence of zoo visitors on the behavior of captive primates. Appl. Anim. Behav. Sci. 1992, 35, 189-198. [CrossRef]

26. Williams, E.; Carter, A.; Rendle, J.; Ward, S.J. Understanding impacts of zoo visitors: Quatifying behavioural changes of two popular zoo species during COVID-19 closures. Appl. Anim. Behav. Sci. 2021, 236, 1-8. [CrossRef]

27. Hosey, G.; Melfi, V.; Ward, S.J. Problematic Wildlife II; Springer Nature Switzerland AG: Cham, Switzerland, 2020 ; pp. 485-508.

28. Binding, S.; Farmer, H.; Krusin, L.; Cronin, K. Status of animal welfare research in zoos and aquariums: Where are we, where to next? J. Zoo Aquar. Res. 2020, 8, 166-174.

29. Freeland, L.; Ellis, C.; Michaels, C.J. Documenting aggression, dominance and the impacts of visitor interaction on Galápagos tortoises (Chelonoidis nigra) in a zoo setting. Animals 2020, 10, 699. [CrossRef]

30. Chamove, A.S.; Hosey, G.; Schaetzel, P. Visitors excite primates in zoos. Zoo Biol. 1988, 7, 359-369. [CrossRef] 
31. Sherwen, S.L.; Harvey, T.J.; Magrath, M.J.; Butler, K.L.; Fanson, K.V.; Hemsworth, P.H. Effects of visual contact with zoo visitors on black-capped capuchin welfare. Appl. Anim. Behav. Sci. 2015, 167, 65-73. [CrossRef]

32. Seebacher, F.; Grigg, G.C.; Beard, L.A. Crocodiles as dinosaurs: Behavioural thermoregulation in very large ectotherms leads to high and stable body temperatures. J. Exp. Biol. 1999, 202, 77-86. [PubMed]

33. Pough, F.H. Amphibians and reptiles as low-energy systems. In Behavioural Energetics: The Cost of Survival in Vertebrates; Aspey, W.P., Lustick, S., Eds.; Ohio State University Press: Columbus, OH, USA, 1983; pp. 141-188.

34. Carr, C.E.; Christensen-Dalsgaard, J.; Bierman, H. Coupled ears in lizards and crocodilians. Biol. Cybernetics. 2016, 110, $291-302$. [CrossRef]

35. Higgs, D.; Brittan-Powel, E.; Soares, D.; Souza, M.; Carr, C.; Dooling, R.; Popper, A. Amphibious auditory responses of the American alligator (Alligator mississipiensis). J. Comp. Physiol. 2002, 188, 217-223.

36. Vergne, A.L.; Pritz, M.B.; Mathevon, N. Acoustic communication in crocodilians: From behaviour to brain. Biol. Rev. 2009, 84, 391-411. [CrossRef] [PubMed]

37. Wever, E.G. Sound transmission in the salamander ear. Proc. Natl. Acad. Sci. USA 1978, 75, 529-530. [CrossRef] [PubMed]

38. Garrick, L.D.; Lang, J.W. Social signals and behaviors of adult alligators and crocodiles. Amer. Zool. 1977, 17, 225-239. [CrossRef]

39. Nagloo, N.; Collin, S.P.; Hemmi, J.M.; Hart, N.S. Spatial resolving power and spectral sensitivity of the saltwater crocodile, Crocodylus porosus, and the freshwater crocodile, Crocodylus johnstoni. J. Exp. Biol. 2016, 219, 1394-1404. [CrossRef] [PubMed]

40. Brien, M.L.; Lang, J.W.; Webb, G.J.; Stevenson, C.; Christian, K.A. The good, the bad, and the ugly: Agonistic behaviour in juvenile crocodilians. PLoS ONE. 2013, 8, 1-12. [CrossRef] [PubMed]

41. Bolker, B.M.; Brooks, M.E.; Clark, C.J.; Geange, S.Q.; Poulsen, J.R.; Stevens, M.H.H.; White, J.S.S. Generalized linear mixed models: A practical guide for ecology and evolution. Trends Ecol. Evol. 2009, 24, 127-135. [CrossRef]

42. Zuur, A.F.; Ieno, E.N.; Elphick, C.S. A protocol for conducting and presenting results of regression-type analyses. Methods Ecol. Evol. 2010, 7, 636-645. [CrossRef]

43. Quinn, G.P.; Keough, M.J. Experimental Design and Data Analysis for Biologists; Cambridge University Press: Cambridge, UK, 2002.

44. Mundry, R. Issues in information theory-based statistical inference-A commentary from a frequentist's perspective. Behav. Ecol. Sociobio. 2011, 65, 57-68. [CrossRef]

45. Mundry, R.; Nunn, C.L. Stepwise model fitting and statistical inference: Turning noise into signal pollution. Am. Nat. 2009, 173, 119-123. [CrossRef] [PubMed]

46. Wood, W. Interactions among environmental enrichment, viewing crowds, and zoo chimpanzees (Pan troglodytes). Zoo Biol. 1998, 17, 211-230. [CrossRef]

47. Dufour, V.; Sueur, C.; Whiten, A.; Buchanan-Smith, H.M. The impact of moving to a novel environment on social networks, activity and wellbeing in two new world primates. Am. J. Primatol. 2011, 73, 802-811. [CrossRef] [PubMed]

48. Stagni, E.; Normando, S.; de Mori, B. Distances between individuals in an artificial herd of African elephants (Loxodonta africana africana) during resource utilisation in a semi-captive environment. Res. Vet. Sci. 2017, 113, 122-129. [CrossRef]

49. Kleinhappel, T.K.; Pike, T.W.; Burman, O.H.P. Stress-induced changes in group behaviour. Sci. Rep. 2019, 9, 1-9.

50. Hamilton, W.D. Geometry for the selfish herd. J. Theor. Biol. 1971, 31, 295-311. [CrossRef]

51. Treves, A. Theory and method in studies of vigilance and aggregation. Anim. Behav. 2000, 60, 711-722. [CrossRef] [PubMed]

52. Ganswindt, S. Non-Invasive Assessment of Adrenocortical Function in Captive Nile Crocodiles (Crocodylus niloticus) and its Relation to Housing Conditions. Master's Thesis, University of Pretoria, Pretoria, South Africa, 2012.

53. Veldsman, D.M. Effects of stocking density on production and behaviour of farmed grower Nile crocodiles (Crocodylus niloticus). Master's Thesis, University of Pretoria, Pretoria, South Africa, 2019.

54. De Vere, A.J. Visitor effects on a zoo population of California sea lions (Zalophus californianus) and harbor seals (Phoca vitulina). Zoo Biol. 2018, 37, 162-170. [CrossRef] [PubMed]

55. Choo, Y.; Todd, P.A.; Li, D. Visitor effects on zoo orangutans in two novel, naturalistic enclosures. Appl. Anim. Behav. Sci. 2011, 133, 78-86. [CrossRef]

56. Downs, C.T.; Greaver, C.; Taylor, R. Body temperature and basking behavior of Nile crocodiles (Crocodylus niloticus) during winter. J. Therm. Biol. 2008, 33, 185-192. [CrossRef]

57. Srivastava, A.; Borries, C.; Sommer, V. Homosexual mounting in free-ranging female Hanuman langurs (Presbytis entellus). Arch. Sex. Behav. 1991, 20, 487-512. [CrossRef] [PubMed]

58. Cordischi, C.; Cozzolino, R.; Aureli, F.; Scucchi, S. Influence of context on mounting and presenting among mature male Japanese macaques. Folia Primatologica. 1991, 56, 211-213. [CrossRef] [PubMed]

59. Maréchal, L.; Maclarnon, A.; Majolo, B.; Semple, S. Primates' behavioural responses to tourists: Evidence for a trade-off between potential risks and benefits. Sci. Rep. 2016, 6, 1-11. [CrossRef] [PubMed]

60. du Preez, M.; Govender, D.; Kylin, H.; Bouwman, H. Metallic elements in Nile Crocodile eggs from the Kruger National Park, South Africa. Ecotoxicol. Envir. Safety 2018, 148, 930-941. [CrossRef]

61. Behangana, M.; Magala, R.; Katumba, R.; Ochanda, D.; Kigoolo, S.; Mutebi, S.; Dendi, D.; Luiselli, L.; Hughes, D.F. Ontogenetic habitat use and seasonal activity of Nile crocodiles (Crocodylus niloticus) in the Lake Albert delta, East Africa. J. Great Lakes Res. 2020, 46, 1776-1782. [CrossRef]

62. Kofron, C.P. The reproductive cycle of the Nile crocodile (Crocodylus niloticus). J. Zool. London. 1990, 221, 477-488. [CrossRef] 
63. Seebacher, F.; Shine, R. Evaluating thermoregulation in reptiles: The fallacy of the inappropriately applied method. Physiol. Biochem. Zool. 2004, 77, 688-695. [CrossRef] [PubMed]

64. Spain, M.S.; Fuller, G.; Allard, S.M. Effects of habitat modifications on behavioral indicators of welfare for Madagascar giant hognose snakes (Leioheterodon madagascariensis). Anim. Behav. Cogn. 2020, 7, 70-81. [CrossRef]

65. Bashaw, M.J.; Gibson, M.D.; Schowe, D.M.; Kucher, A.S. Does enrichment improve reptile welfare? Leopard geckos (Eublepharis macularius) respond to five types of environmental enrichment. Appl. Anim. Behav. Sci. 2016, 184, 150-160. [CrossRef]

66. Benn, A.L.; McLelland, D.J.; Whittaker, A.L. A review of welfare assessment methods in reptiles, and preliminary application of the welfare quality®protocol to the pygmy blue-tongue skink, Tiliqua adelaidensis, using animal-based measures. Animals 2019, 9, 27. [CrossRef] [PubMed]

67. Leeds, A.; Stone, D.; Johnson, B.; Less, E.; Schoffner, T.; Dennis, P.; Lukas, K.; Wark, J. Managing repetitive locomotor behaviour and time spent off exhibit in a male black-footed cat (Felis nigripes) through exhibit and husbandry modifications. J. Zoo Aquar. Res. 2016, 4, 109-114.

68. Ross, S.R.; Schapiro, S.J.; Hau, J.; Lukas, K.E. Space use as an indicator of enclosure appropriateness: A novel measure of captive animal welfare. Appl. Anim. Behav. Sci. 2009, 121, 42-50. [CrossRef] 